\title{
Product redesign to align with production processes
}

\section{Rediseño de producto para alinear con procesos de producción}

\author{
OJEDA-ESCOTO, Pedro Agustín†** \\ Universidad Tecnológica de Aguascalientes, Industrial Electromechanics and Renewable Energies Division. Blvd. Juan \\ Pablo II 1302 Exhacienda la Cantera, C.P. 20200, Aguascalientes, Mexico.
}

ID $1^{\text {st }}$ Author: Pedro Agustín, Ojeda-Escoto / ORC ID: 0000-0001-7282-4672, CVU CONACYT ID: 50027

\begin{abstract}
The development of products destined to cover specific needs plays an important role when it is possible to have feedback, in terms of functionality, on the part of the final user for the consolidation of the product. Seeking such consolidation and identifying opportunities for improvement, in this paper a redesign was made based on specific criteria to align the manufacturing to mass production. The following premises were raised: 1) validation of the de-sign proposal; 2) comparative and operational analysis; 3) geometry optimization for weight and production cost reduction. This paper proposes a new design of the drawbar body of a tractor (case study) and the theoretical framework is established taking the bases of the concurrent engineering to define and characterize the final architecture configuration. Is reported the methodology used for the development of this research and the results obtained by finite element analysis for architecture optimization. Finally, are presented the defined strategies for aligning manufacturing to production.
\end{abstract}

Redesign, characterization, optimization

\section{Resumen}

El desarrollo de productos destinados a cubrir necesidades específicas juega un papel importante cuando es posible tener una retroalimentación, en términos de funcionalidad, por parte del usuario final para la consolidación del producto. Buscando dicha consolidación e identificando oportunidades de mejora, en este documento se ha realizado un rediseño basado en criterios específicos para alinear la fabricación a producción en serie. Se plantearon las siguientes premisas: 1) validación de la propuesta de diseño; 2) análisis comparativo y operacional; 3) optimización de la geometría para reducir el peso y los costos de producción. En el presente trabajo se propone un nuevo diseño del cuerpo de la barra de tracción de un tractor (caso de estudio) y se establece el marco teórico tomando las bases de la ingeniería concurrente para definir y caracterizar la configuración de la arquitectura final. Se reporta la metodología utilizada para el desarrollo de esta investigación y de los resultados obtenidos por el análisis de elementos finitos para la optimización de la arquitectura. Finalmente, se presentan las estrategias definidas para alinear la fabricación con la producción.

Rediseño, caracterización, optimización

Citation: OJEDA-ESCOTO, Pedro Agustín. Product redesign to align with production processes. Rinoe Journal-Industrial Organization. 2020. 4-6:1-9.

\footnotetext{
*Correspondence to Author (Email: pedro.ojeda@utags.edu.mx)

$\dagger$ Researcher contributing first author.
} 


\section{Introduction}

Most structured methodologies to generate redesign seek to renew products from a particular approach, to mention a few: assembly, manufacturing, production, design for X. Taking traditional research as a starting point, in his work Pugh [1] presents a novelty of his Total Design Model to face the redesign. In this novelty, the specification of a product is established after having analyzed its concept, so it is used as a requirement to propose a variant solution. Some other design models are based on the execution and evaluation stages, or on the optimization of an initial alternative ([2], [3]).

Following this context, the initial solution option is evaluated and improved taking into account different aspects, such as: performance, cost, assembly, functionality, reliability, maintainability. Feedback is enforced, so the initial concept can be modified. Mostow [4] proposes a method to redesign, known as the repetition and modification paradigm. It consists of repeating a previous design process and modifying actions whenever necessary and possible according to the original design intent for new design specifications.

Studies by Han \& Lee [5] and Howard et al. [6] define and treat redesign as a resolution of conflicts between current product needs and previous design capabilities; they also document that innovative products are only introduced when there are major conflicts between customer needs and existing products. On the other hand, Smith et al. [7] describe that there are many reasons to redesign a product and the design is usually derived from similar products; focusing their study on which redesign is an important part of the process of developing a new product.

One of the advantages of implementing redesign as a product development technique is being able to analyze not only design and assembly issues, but also strategies for planning and implementing proper disassembly of existing elements and subsystems. In the engineering context, disassembly may be defined as the use of assembly methods and configurations that allow for development of product cost-effective facilitates the separation of components and materials from used product to encourage recovery and reuse [8].
Disassembly is required for recycling, maintenance, remanufacturing, etc. Pertaining to remanufacturing, prioritization and protection of cores over nonremanufacturable parts are some aspects to be considered during the disassembly process [9].

This paper reports the procedure of the redesign done to the drawbar body of a tractor (case study). It also reports the results obtained from the finite element analysis made to that hitch to optimize its final architecture. Finally, defined strategies to align manufacturing to production are mentioned.

\section{Theoretical Framework}

The research presented in this paper is mainly based on the bases of Concurrent Engineering (CE) as regards technical processes. Some redesign perspectives were also taken into account in order to determine and define the final architecture of the coupling (case study). An overview of these issues is presented below.

\section{Concurrent Engineering}

The beginnings of Concurrent Engineering (CE) emerged from the aerospace industry, where all processes are governed by two main ideas: a) All components and elements of the final product must be considered from the earliest stages of design, and b) All the design activities preceding the achievement of the product must be taking place at the same time, i.e. they must be moving forward in the process simultaneously.

Once the CE is contextualized, which is currently closely related to the development of new products, it can be defined as the process of developing new products in which all areas must be involved, working accordingly in the creation of the product. Apart from being a mere work philosophy, CE involves a series of work techniques that allow to considerably shorten the development time of a product, allowing to reduce its costs, increase its quality and therefore, improve it.

According to Borja [10], there are several definitions of CE or also called in some research as Simultaneous Engineering (SE). 
There are some other definitions [11], but all of them agree that SE belongs to the design process, and assigns parallel activities to decrease the product development time, improving its quality by integrating the product and its manufacturing process [12] (Figure 1).

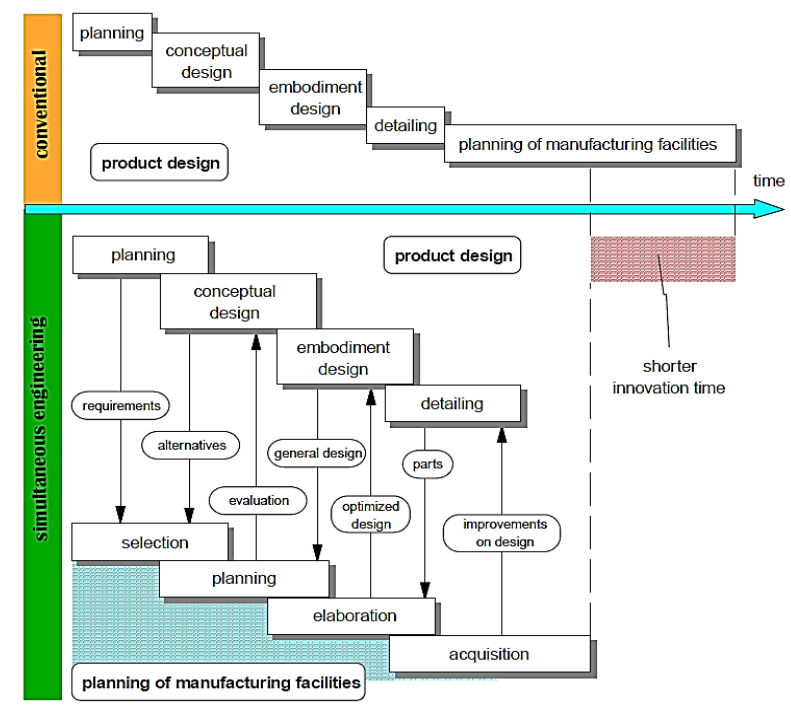

Figure 1 Simultaneous Engineering

Source: Borja [10]

According to Figure 1, the SE approach is to consider all aspects of the product life cycle as early as possible in the design process. The quality of products and its processes is improved because designs fulfil expectations of customers, are easy to produce and maintain. Important cost reductions can be achieved avoiding changes in the later stages of the design process and simplifying the production. And the lead time both for the design process (time to release a product to production) and to market (time to deliver the product to the customer) is shortened, due to parallel activities and the integration of the design of the product and its manufacturing process. Common problems that make it necessary to implement the $\mathrm{CE}$ in the design or redesign of a new product are:

- Increased product variety and technical complexity that prolongs the product development process and makes it difficult to predict the impact of design decisions on the functionality and performance of the final product.

- Increase the global competitive pressure resulting from the emerging concept of reengineering.

- The need for a rapid response to changing consumer demand.
- $\quad$ The need for a shorter product life cycle.

- Large organisations with several departments working on the development of numerous products at the same time.

- New and innovative technologies that emerge at a very high rate, making the new product technologically obsolete in a short period of time.

Finally, some improvements to specific product lines through the application of concurrent engineering are:

- Optimization of development and production times.

- Quality system improvements.

- Improvements in engineering processes.

- Cost reduction.

\section{Redesign Perspectives}

Much of the design activity that companies have is concentrated on product re-design and usually a new product is a variation of the previous ones. Van Eldonk et al. [13] also add that it is not common to start the design of such a product from scratch, since companies make use of previous experience; to develop products that include functions and improvements, research and development is required and this also requires adjustments in manufacturing processes or the implementation of new ones.

Adam et al., [14] synthesize some methods that can be used for the implementation of product redesign:

- One of them involves the use of reverse engineering techniques (making it very clear that reverse engineering is the opposite of advanced engineering). An existing product is taken and the corresponding $\mathrm{CAD}$ model is generated for modification or reproduction of the product disk design aspects. Reverse engineering is used to redesign a system to improve manufacturing or to produce a copy of the system without accessing the design from which it was originally produced. 
- Another path to redesign includes the integration of scanned images and drawings during the modelling process. These images serve as a guide to the designer when modelling the virtual object. In the end, the obtained configurations are used to improve the geometry of the new product.

- A further method is the disassembly of a product (or more) where the redesign is used to enhance certain features (new functions) in order to attach them to new components.

\section{Research methodology, analysis and results}

Designing is establishing and defining relevant solutions and structures, for problems that have not been solved before or new solutions proposed in a different way for problems that have previously been solved. Therefore, many designers argue that the only way to learn the artistic part of design is by designing.

Is also important to mention that many times it is required for the benefit of the advance of an investigation that they follow methodologies already defined or that they follow some variant based on those already mentioned. Figure 2 presents the methodology proposed for the development of this work.

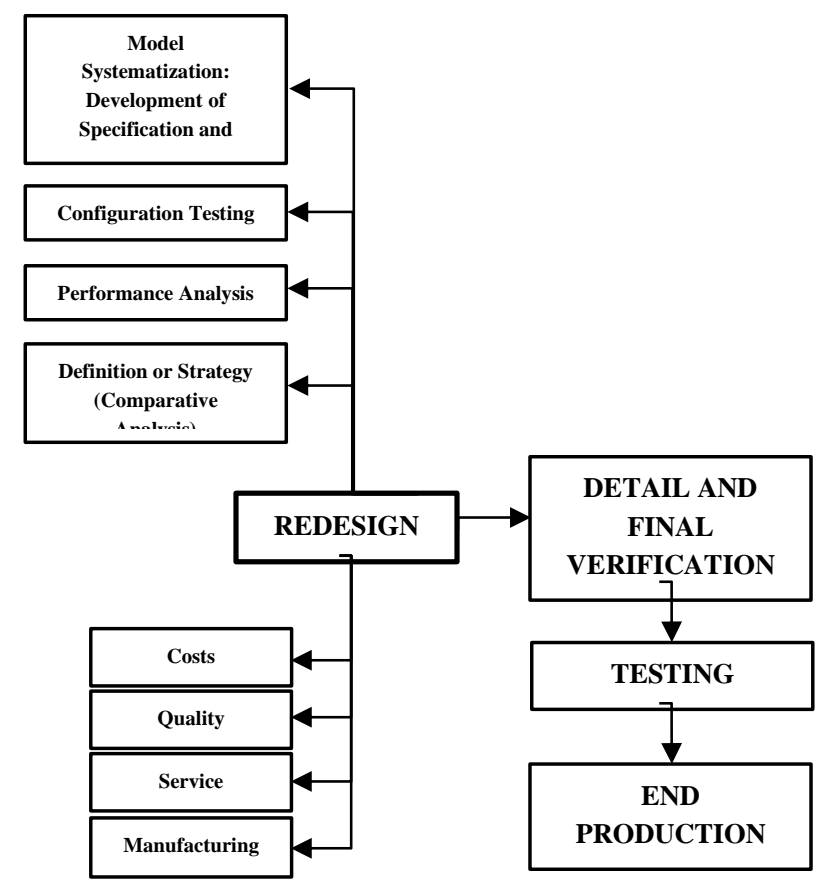

Figure 2 Research methodology Source: Own production
Below is an overview of each of the stages of the methodology implemented:

- Definition or Strategy (Comparative Analysis): Analysis carried out to define the new concept of the drawbar body.

- Performance Analysis: Definition of FEA analysis to locate the best redesign solution.

- Configuration Testing: Test stage for assembly and disassembly of components.

- Model Systematization (Development of Specification and Conceptualization): Conceptualization of the final product architecture.

- Costs: Cost analysis in design and manufacturing stage.

- Quality: Analysis and implementation of quality in manufacturing processes.

- Service: Implementation of the necessary conditions for the application of manufacturing processes.

- Manufacturing: Implementation of manufacturing processes and continuous improvement.

- DETAIL AND FINAL VERIFICATION: Numerical analysis of FEA results and first stage of physical tests.

- TESTING: Second stage of physical testing under real operating conditions.

- END PRODUCTION: Alignment of product manufacturing to final production taking into account the strategies mentioned in section 3.4.

\section{Case Study}

The case study referred to in this article concerns the modification of the drawbar body of a tractor. This tractor is distributed in Mexico by a 100\% Mexican company dedicated to offering integral solutions in the agricultural area. 


\section{Proposition}

In accordance with the requested requirement: increase the distance between the tow bar and the floor, several alternatives were proposed and reviewed to provide a solution to this requirement. Several ideas were conceptualized in which different changes were intended to be made, either partially or considerably.

Finally, it was decided to choose the one that avoids making very significant changes in the subassembly of the hitch. Figure 3 shows the final geometry proposed for the tractor pull modification.

\section{Geometry optimization}

Once the geometry was defined, finite element analyses were performed to corroborate or optimize (if required) the selected coupling geometry. These analyses also served to evaluate the weld and define the pro-posed application of the weld (Figure 4).

The mesh of the model was generated based on the dimensional relationships between the components of the assembly.
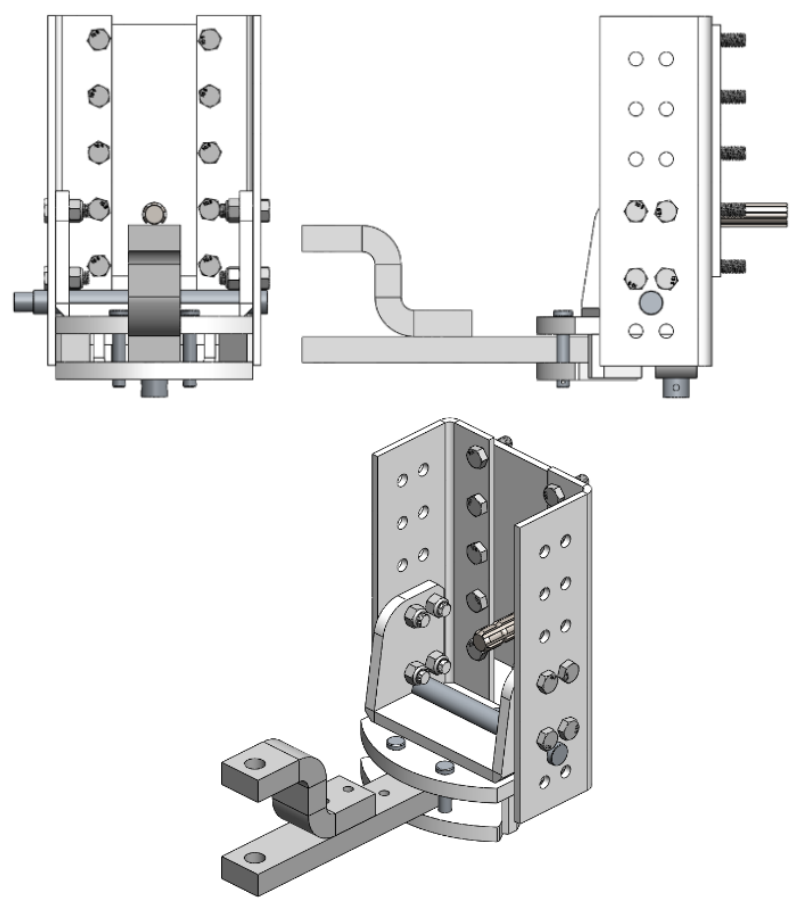

Figure 3 Modified coupler geometry

Source: Own production

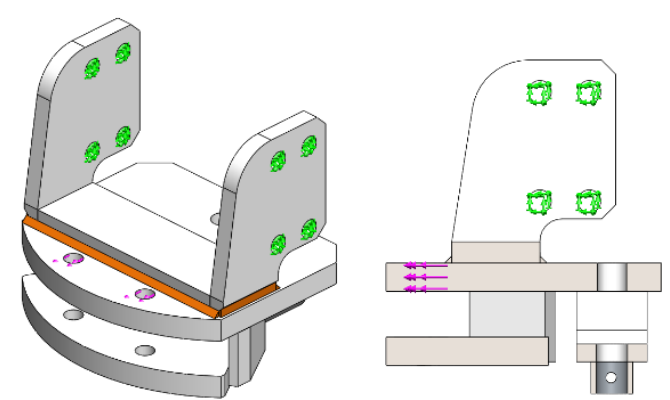

a)
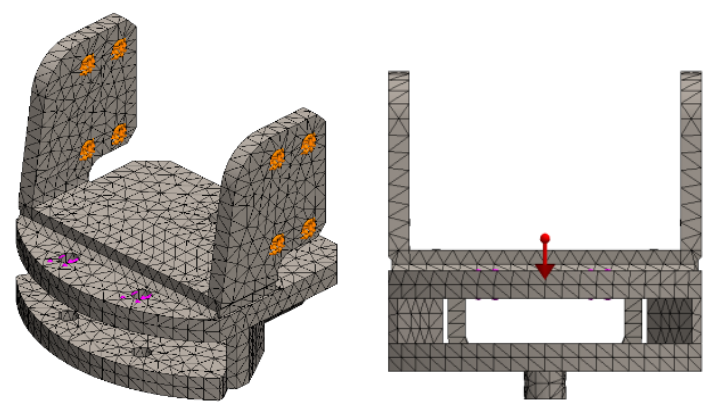

b)

Figure 4 Application of border conditions: a) Model preparation, b) Model meshing

Source: Own production

The load conditions proposed for the analysis were determined based on the solicitations that are presented in the normal pull work exerted by the tractor. The load applied for the simulation of the tractor pull was of a magnitude of 9 tons.

Once the model had been characterized, a series of FEA analyses were carried out to evaluate the behavior of the elements that make up the assembly and how the applied welding would respond. Figure 5 shows the final geometry selection of the results obtained by finite element. 


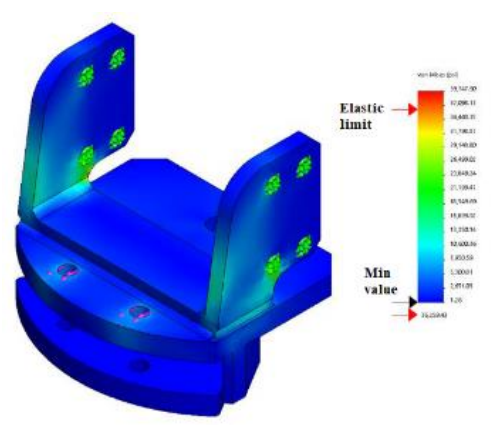

a)

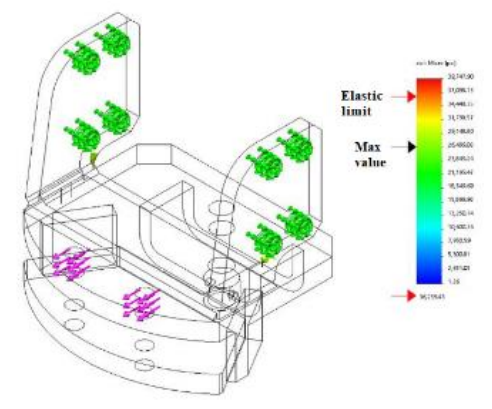

b)

Figure 5 Stress analysis results: a) Elastic limit, b) Maximum stress value

Source: Own production

\subsection{Results and Discussion}

The stress study carried out on the modified coupling assembly shows that each and every one of the elements that make up the coupling has stress values below the permissible elastic limit of the material.

Figure 6 shows the result obtained from the finite element analysis applied to the new coupling proposal and taking into account the stresses presented on the pull bar attached to the coupling.

In the area where the coupling assembly surrounds the reinforcement bar of the external cylinder that supports the lift is where the highest magnitudes of efforts are presented presenting concentration of efforts in some points, this is due to the same geometry and conditions under which the elements of this part work.

Even so, these magnitudes are within the normal deformation ranges so that, for the time being, they can be neglected in order to continue with the manufacturing of the final assembly.

Finally, Figure 7a) shows the defined increase in the distance between the hitch bar and the ground and Figure 7b) shows the final assembly of the hitch on the corresponding tractor.

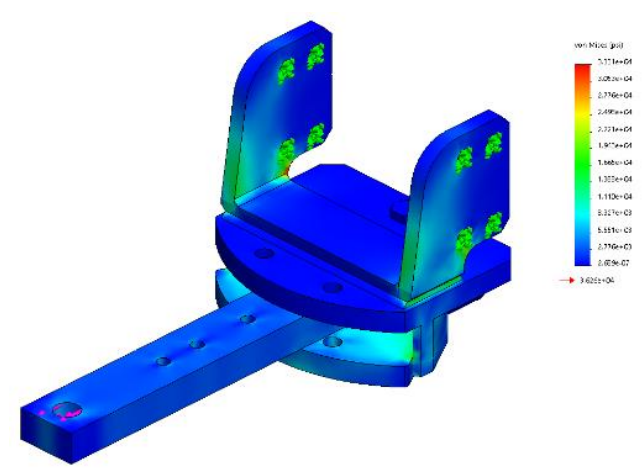

a)

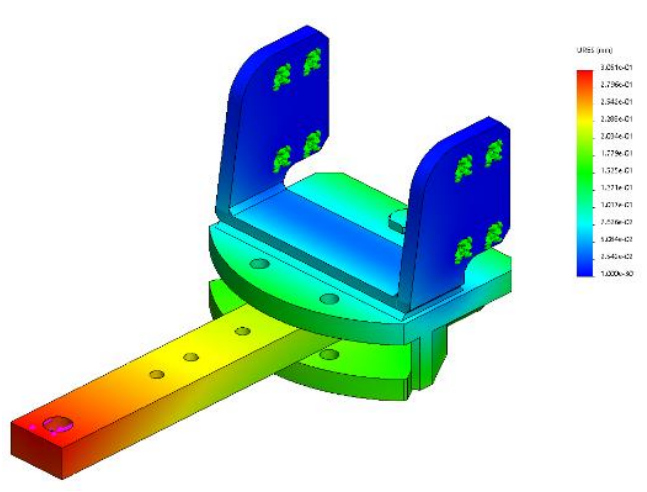

b)

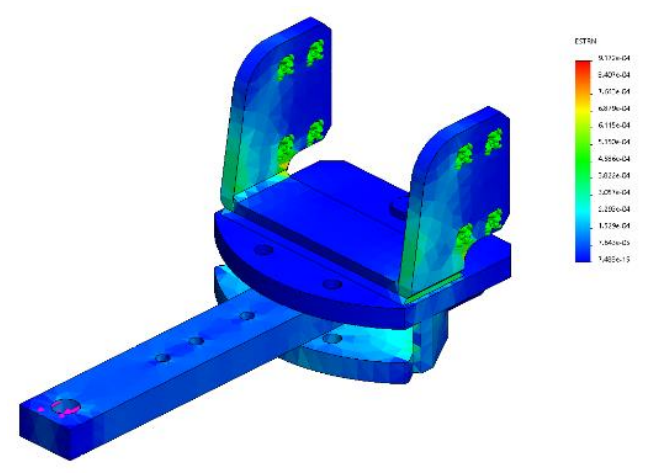

c)

Figure 6 Results of the analysis with the drawbar attached to the hitch: a) Stress Analysis, b) Displacement Analysis, c) Unit Deformation Analysis

Source: Own production

\subsection{Comparison of Original Solution and New Proposal}

Figure 8 shows the results of the FEA analysis study carried out on the original geometry of the hitch, although the magnitudes of the stresses are below the elastic limit of the material, is possible to observe that the highest concentration is in the coupling plate of the tractor body. In the proposal chosen to implement the redesign of this coupling (Fig. 6), can be seen that, by changing the geometry of the coupling plate, stress concentrations decrease considerably. 


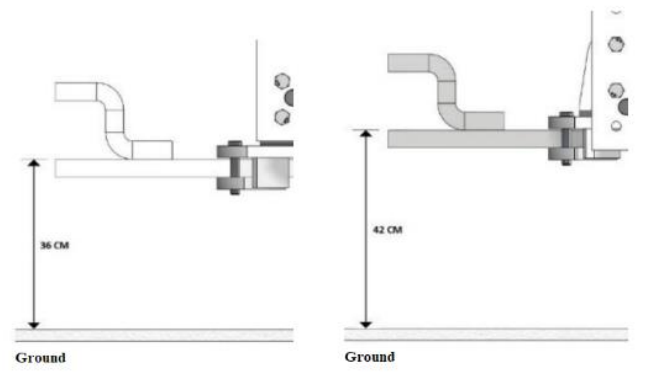

a)

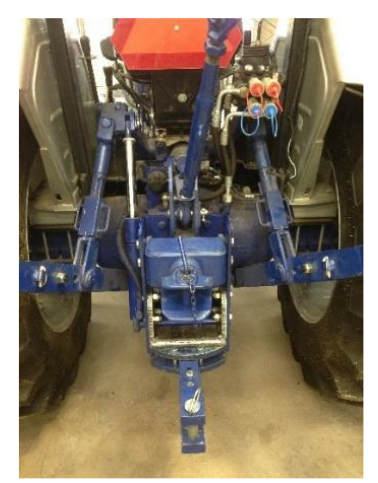

b)

Figure 7 Final results: a) Distance between hitch bar and ground: original and modified pull, b) Final assembly on the tractor

Source: Own production
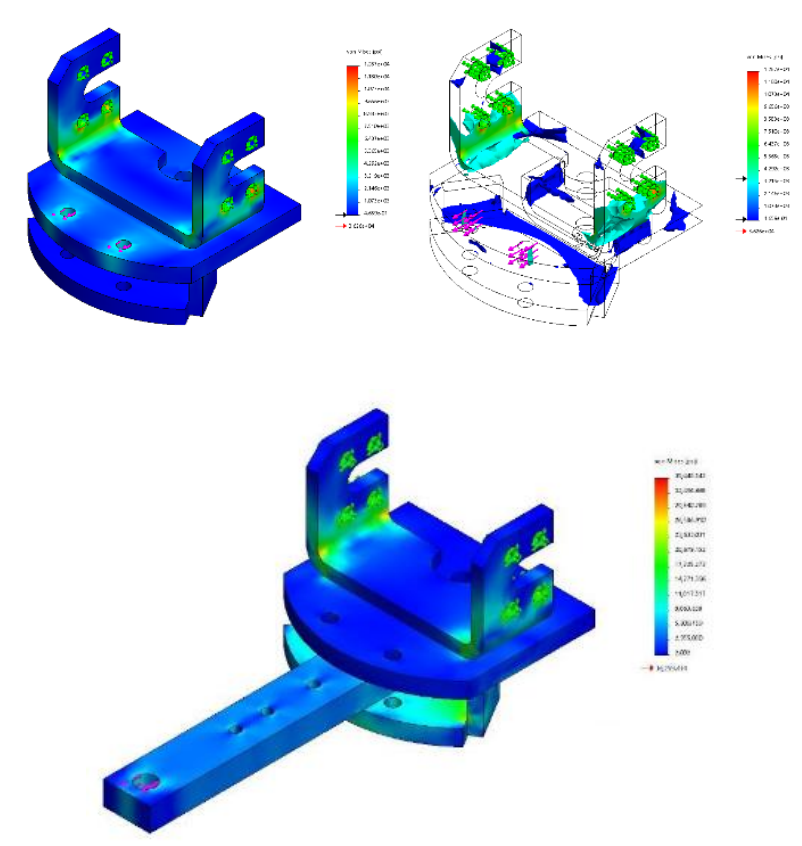

Figure 8 Stress analysis results of the original geometry and with the drawbar attached to the hitch Source: Own production

Based on the results obtained from the finite element analysis of the geometries (existing and selected for new proposal), the value is increased to the argument that the new geometry will have better response to the tractor working loads and therefore a plus is added to the technical specification.
Is also important to comment that these results served as the basis for generating the alignment strategies for manufacturing and production.

\section{Strategies for production alignment}

Once the new architecture of the coupling was defined and the tests of the product concept were carried out, the following strategies were defined to align it to production, taking into account product image and marketing (due to confidentiality issues of the company, these strategies are mentioned in a very global way) (Figure 9).

A. Product development and evaluation (customer projection)

B. Marketing (market share; product costs; product positioning; sales target)

\section{Commercial viability (evaluate commercial} attractiveness; expected costs and benefits of (1.............

D. Merchandising (decision making for product launch)

E. Market test (introduction to a realistic environment; sales projection)

Figure 9 Strategies for alignment to production Source: Own production

The strategies mentioned above together with the defined manufacturing processes, complemented the final line for the generation of different families of couplings according to each of the existing tractor models.

Finally, a successful sales scenario was obtained for these couplings based on the experimental and engineering results applied in this research.

\section{Conclusions}

Advances in computer and technology analysis allow engineers and researchers to have effective diagnostic and simulation tools that facilitate, at any given time, the design, redesign or optimization of a mechanical system. 
The development and implementation of methodologies for the design or redesign of products based on new technologies, increases the probability of market alignment and the increase of knowledge and technology transfer to the industrial sector.

Designing is establishing and defining relevant solutions and structures, for problems that have not been solved before or new solutions posed differently for problems that have been previously solved.

In this paper, the configuration of a tractor's hitch body and the results of the finite element analysis were presented as a case study that helped to define a redesign of the final architecture of that hitch. Finally, some defined strategies were listed for the alignment of the new product developed to production, taking into account sales projections, product image and marketing.

\section{Acknowledgment}

The author of this paper is grateful for the technical, economic and logistical support of the Industrial Electromechanics and Renewable Energy Division of the Technological University of Aguascalientes.

\section{References}

[1] Pugh, S.: Total Design. Addison Wesley, Great Britain (1990).

[2] Ullman, D. G.: The Mechanical Design Process, Mc. Graw-Hill, New York (1992).

[3] Ulrich, K.T., Eppinger, S.D.: Product design and development, Mc. Graw-Hill, International Editions (1995).

[4] Mostow, J.: Design by derivational analogy: Issues in the automated replay of design plans, Artificial Intelligence, Elsevier Ltd. Journals 40(1-3), 119-184 (1989).

[5] Han, Y.H., Lee, K.: A case-based framework for reuse of previous design concepts in conceptual synthesis of mechanisms. Computers in Industry, Elsevier Ltd. Journals 57(4), 305-318 (2006).
[6] Howard, T.J., Culley, S.J., Dekoninck, E.A.: Reuse of ideas and concepts for creative stimuli in engineering design. Journal of Engineering Design 22(8), 565-581 (2011).

[7] Smith, S., Smith, G., Shen, Y.: Redesign for product innovation. Design Studies, Elsevier Ltd. Journals 33(2), 160-184 (2012).

[8] Mule, J.: Design for Disassembly Approaches on Product Development. International Journal of Scientific \& Engineering Research 3(6), 1-5 (2012).

[9] Soh, S., Ong, S., Nee, A.: Application of Design for Disassembly from Remanufacturing Perspective. 12th Global Conference on Sustainable Manufacturing. Elsevier 26, 577-582 (2015).

[10] Borja, R.V.: Redesign supported by data models with particular reference to reverse engineering. Doctoral Thesis of Loughborough University (1997).

[11] Dowlatshahi, S.: A comparison of approaches to concurrent engineering. The International Journal of Advanced Manufacturing Technology, SpringerVerlag London Limited 9, 106-113 (1994).

[12] Sohlenius, G.: Concurrent Engineering. Annals of the CIRP 41(2), 645-655 (1992).

[13] Van Eldonk, S.J.M., Alberts, L.K., Bakker, R.R., Dikker, F.: Wognum, P.M., Redesign of technical systems. Knowledge-Based Systems, Elsevier Ltd. Journals 9, 93-104 (1996).

[14] Adam, A., Cosma, C., Cosma, A., Pop, A.: Redesigning a product using modern CAD-CAM software. 8th International Conference Interdisciplinary in Engineering, Elsevier Ltd., Procedia Technology 19, 221-227 (2015).

[15] Wognum, P.M., Smith, I.F.C.: Reuse of designs. Knowledge-Based Systems, Elsevier Science B.V. 9, 79-81 (1996). 
[16] Ullah, I., Tang, D., Yin, L.: Engineering product and process design changes: $\mathrm{A}$ literature overview. 9th International Conference on Digital Enterprise Technology, Procedia CIRP 56, 25-33 (2016).

[17] Zhan-Shan, L., Fei-Hong, K., Xiao-Chun, C., Tao, W.: Model-Based Product Redesign, International Journal of Computer Science and Network Security 6(1A), 99-103 (2006).

[18] Ullah, I., Tang, D., Wang, Q., Yin, L., Hussain, I.: Managing engineering change requirements during the product development process. Concurrent Engineering Research and Applications, SAGE Publications Journals 00(0), 1-16 (2017).

[19] Evbuomwan, N.F.O., Sivaloganathan, S., Jebb, A.: A Survey of Design Philosophies, Models, Methods and Systems. Proceedings of the Institution of Mechanical Engineers, Part B: Journal of Engineering Manufacture 210, 301-320 (1996).

[20] Janhager, J.: Hierarchical Decomposition of Technical Functions and User Actions. Proceedings of the ASME Design Engineering Technical Conferences and Computers and Information in Engineering Conference (2003).

[21] Hubka, V., Eder, W.E.: Engineering Design - General Procedural Model of Engineering Design, Heuristic Edition, Zürich (1992). 